\title{
Postoperative Non-Pathological Fever Following Posterior Cervical Fusion Surgery : Is Laminoplasty a Better Preventive Method than Laminectomy?
}

\author{
Subum Lee, Sang Ku Jung, ${ }^{2}$ Hong Bum Kim, ${ }^{1}$ Sung Woo Roh, ${ }^{1}$ Sang Ryong Jeon, Jin Hoon Park ${ }^{1}$ \\ Department of Neurological Surgery, ${ }^{1}$ Asan Medical Center, University of Ulsan College of Medicine, Seoul, Korea \\ Department of Emergency Medicine, ${ }^{2}$ Gangneung Asan Hospital, University of Ulsan College of Medicine, Gangneung, Korea
}

Objective : To analyze the incidence and characteristics of delayed postoperative fever in posterior cervical fusion using cervical pedicle screws (CPS).

Methods : This study analyzed 119 patients who underwent posterior cervical fusion surgery using CPS. Delayed fever was defined as no fever for the first 3 postoperative days, followed by an ear temperature $\geq 38^{\circ} \mathrm{C}$ on postoperative day 4 and subsequent days. Patient age, sex, diagnosis, laminectomy, surgical level, revision status, body mass index, underlying medical disease, surgical duration, and transfusion status were retrospectively reviewed.

Results : Of 119 patients, seven were excluded due to surgical site infection, spondylitis, pneumonia, or surgical level that included the thoracic spine. Of the 112 included patients, $28(25 \%)$ were febrile and $84(75 \%)$ were afebrile. Multivariate logistic regression analysis showed that laminectomy was a statistically significant risk factor for postoperative non-pathological fever (odds ratio, $10.251 ; p=0.000$ ). In contrast, trauma or tumor surgery and underlying medical disease were not significant risk factors for fever.

Conclusion : Patients who develop delayed fever 4 days after posterior cervical fusion surgery using CPS are more likely to have non-pathologic fever than surgical site infection. Laminectomy is a significant risk factor for non-pathologic fever.

Key Words : Fever · Laminectomy · Laminoplasty · Posterior cervical · Seroma.

\section{NTRODUCTION}

Fever above $38^{\circ} \mathrm{C}\left(100.4^{\circ} \mathrm{F}\right)$ is common in the first few days after major surgery ${ }^{7,8)}$. Although fever may be caused by infection of the surgical site, most early postoperative fever is caused by surgery-induced inflammation and resolves spontaneously ${ }^{9,12,19)}$. Moreover, the likelihood of early postoperative fever tends to be greater in patients who have undergone longer and more extensive surgical procedures ${ }^{5)}$.

We often encounter cases in which patients show postoperative fever unrelated to wound infection after spinal surgery. Postoperative fever may appear for a variety of reasons. Prolonged operation time and seroma due to a relatively more extensive surgery are risk factors for non-pathologic fever fol-

- Received : September 18, 2019 •Revised : December 21, 2019 •Accepted : January 20, 2020

- Address for reprints : Jin Hoon Park

Department of Neurological Surgery, Asan Medical Center, University of Ulsan College of Medicine, 88 Olimpic-ro 43-gil, Songpa-gu, Seoul 05505, Korea Tel : +82-2-3010-3550, Fax : +82-2-476-6738, E-mail : jhpark@amc.seoul.kr, ORCID : https://orcid.org/0000-0002-0903-3146 
lowing general spinal surgery ${ }^{23}$. In the clinical field, it is helpful to investigate the incidence and risk factors for delayed postoperative fever as a basis for reducing the cost burden to rule out surgical site infection and to determine the cause of fever. Thus, we retrospectively analyzed postoperative fever in a selective and homogeneous patient population consisting of patients who underwent posterior cervical fusion using cervical pedicle screws (CPS), with or without a subsequent anterior approach $^{4,1718,211}$.

\section{MATERIALS AND METHODS}

The study was approved by the Institutional Review Board of Gangneung Asan Hospital (GNAH 2018-02-001), with the consent process waived owing to the retrospective nature of the study. From March 2012 to December 2017, 119 patients at our institution underwent posterior cervical spinal surgery under general anesthesia. All operations were performed by a single surgeon, who performed all steps from skin incision to closure in all the operations. The minimum patient follow-up period was 6 months. Patients underwent decompression with laminectomy or laminoplasty and fusion using CPS placement. All CPSs were inserted using the freehand technique via a process that followed the safety steps, including repeat balltip probing and checking the feedback of the screw trajectory. If ball-tip probing suggested a pedicle breach, the CPS was converted to a lateral mass screw ${ }^{18,211}$.
Patients underwent surgery for degenerative diseases, trau$\mathrm{ma}$, and tumor. Delayed fever was defined as no fever until postoperative day 3 , followed by an ear temperature $\geq 38.0^{\circ} \mathrm{C}$ on day 4 and on subsequent days. Body temperature was measured at least once every 8 hours. In patients who developed fever, body temperature was measured at least twice every hour. Patients were not considered febrile if they developed fever immediately after surgery to postoperative day 3 , because the cause of fever during that period was surgery-induced trauma (Fig. 1).

To only evaluate patients with non-pathologic fever, patients with infectious conditions were excluded, including patients with wound dehiscence, spondylitis, and postoperative pneumonia. Patients with multiple traumas who required joint surgery in addition to spinal surgery were excluded, as were patients with a surgical level extending beyond the cervical spine.

Patients who underwent surgery from March 2012 to February 2014 were administered cefazolin $1 \mathrm{~g}$ twice daily as a prophylactic antibiotic until postoperative day 3. However, patients who underwent surgery from March 2014 to December 2017 were administered prophylactic cefazolin $1 \mathrm{~g}$ twice daily until postoperative day 1 . No patient received additional antibiotics unless the cause of postoperative fever could not be identified. The origin of fever was always discussed with the patient's medical specialist to exclude infectious causes, thereby excluding patients with drug-related or post-transfusion fever. Surgical site drains were left in all the patients and were

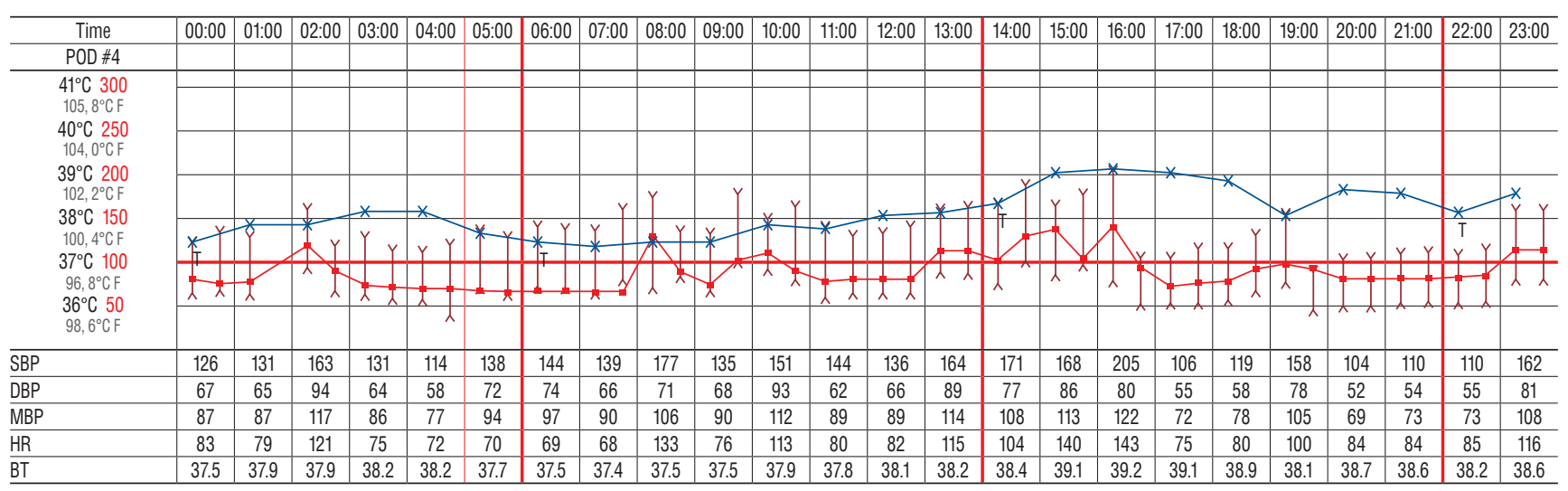

Fig. 1. Sample vital sign chart used at Gangneung Asan Hospital. The blue line marked with an $\mathrm{x}$ indicates the body temperature. The chart shows the vital signs of a patient who visited our emergency center with cervical trauma and underwent cervical laminectomy and fusion surgery using cervical pedicle screw. On the fourth postoperative day, this patient had a body temperature $>38$ degrees Celsius. POD : postoperative days, SBP : systolic blood pressure, DBP : diastolic blood pressure, MBP : mean blood pressure, HR : heart rate, BT : body temperature. 
removed only when the amount of drained fluid was $<100 \mathrm{~mL}$ per day, or $<30 \mathrm{~mL}$ every 8 hours.

Patients' medical charts were reviewed. Data collected included patient age, sex, presence of diabetes mellitus or hypertension, smoking history, body mass index, diagnosis, surgical level, laminectomy or preservation of the lamina, performance of revision surgery, operating time, period of treatment with prophylactic antibiotics, and the performance of transfusion during the perioperative period.

Tests for statistical significance included Student's t-test, Mann-Whitney $\mathrm{U}$ test, chi-squared test, and univariate and multivariate logistic regression. A $p$ value $<0.05$ was defined as statistically significant.

\section{RESULTS}

\section{Demographics of included patients}

Overall, 94 males (84\%) and 18 females (16\%) were enrolled. The mean age was 58.4 years. Among the total number of patients, 108 (96.4\%) underwent a posterior only approach surgery and four (3.6\%) underwent a combined additional anterior approach surgery. Surgeries included 39 (34.8\%) one-level surgeries, 31 (27.7\%) two-level surgeries and 42 (37.5\%) three or more level surgeries. A total of three revisional surgeries were performed, all on patients included in the no fever group. The above patients' demographics were not significantly different between the two groups.

\section{Prevalence of postoperative fever and infection}

Of the 112 patients who met the inclusion criteria, 28 (25\%) were febrile and $84(75 \%)$ afebrile. The culture results for patients with fever were all negative, and none of these patients developed infection of the surgical site for 6 months after surgery.

\section{Risk factors for postoperative fever}

The incidence of laminectomy and trauma or tumor as the underlying medical disease differed significantly in febrile and afebrile patients. The five patients with tumors included one case of schwannoma and four cases of cancer metastasis. There was no significant difference in fever incidence with or without malignancy in tumor patients (Table 1). Of the 112 patients, 59 (52.7\%) underwent laminectomy and 53 (47.3\%) did not. Multivariate logistic regression analysis showed that laminectomy (odds ratio [OR], 10.251; $p=0.000$ ) was a statistically significant risk factor for postoperative non-pathological fever. However, tumor surgery (OR, 2.089; $p=0.543$ compared with degenerative disease or trauma surgery) and underlying medical disease (OR, $2.465 ; p=0.152)$ were not significantly associated with postoperative non-pathological fever (Table 2).

Table 1. Patient demographic and clinical characteristics

\begin{tabular}{|c|c|c|c|}
\hline Variable & $\begin{array}{l}\text { Fever } \\
(n=28)\end{array}$ & $\begin{array}{c}\text { No fever } \\
(n=84)\end{array}$ & $p$-value \\
\hline $\operatorname{Sex}(M: F)$ & $24: 4$ & $70: 14$ & 1.000 \\
\hline Age (years) & $54.9 \pm 13.1$ & $59.5 \pm 12.7$ & 0.144 \\
\hline Surgical approach & & & 0.570 \\
\hline Posterior & $28(100)$ & $80(95.2)$ & \\
\hline Ant. + Post. & $0(0)$ & $4(4.8)$ & \\
\hline Disease & & & 0.006 \\
\hline Trauma & $18(64.3)$ & $34(40.5)$ & \\
\hline $\mathrm{DD}$ & $7(25.0)$ & $48(57.1)$ & \\
\hline Tumor & $3(10.7)$ & $2(2.4)$ & \\
\hline Benign & Schwannoma 1 & 0 & 0.250 \\
\hline Malignant & Metastasis 2 & Metastasis 2 & 0.259 \\
\hline Laminectomy, yes & $24(85.7)$ & $35(41.7)$ & 0.000 \\
\hline Surgical level & & & 0.175 \\
\hline 1 & $6(21.4)$ & $33(39.3)$ & \\
\hline 2 & $7(25.0)$ & $24(28.6)$ & \\
\hline 3 & $7(25.0)$ & $16(19.0)$ & \\
\hline 4 & $8(28.6)$ & $10(11.9)$ & \\
\hline 5 & $0(0)$ & $1(1.2)$ & \\
\hline Revision, yes & $0(0)$ & $3(3.6)$ & 0.572 \\
\hline DM, yes & $5(17.9)$ & $16(19.0)$ & 0.889 \\
\hline HTN, yes & $10(35.7)$ & $25(29.8)$ & 0.556 \\
\hline Medical disease, yes & $10(35.7)$ & $14(16.7)$ & 0.033 \\
\hline Smoking, yes & $13(46.4)$ & $34(40.5)$ & 0.580 \\
\hline Antibiotic duration & & & 0.849 \\
\hline 1 day & $10(35.7)$ & $28(33.7)$ & \\
\hline 3 days & $18(64.3)$ & $55(66.3)$ & \\
\hline Transfusion, yes & $10(35.7)$ & $16(19.0)$ & 0.070 \\
\hline $\mathrm{BMI}\left(\mathrm{kg} / \mathrm{m}^{2}\right)$ & $23.77 \pm 3.18$ & $24.44 \pm 3.34$ & 0.523 \\
\hline Duration of surgery (hours) & $2.95 \pm 1.15$ & $2.96 \pm 1.08$ & 0.793 \\
\hline
\end{tabular}

Values are presented as mean \pm standard deviation or number (\%). M : male, F : female, Ant. : anterior, Post. : posterior, DD : degenerative disease, DM : diabetes mellitus, HTN : hypertension, BMI : body mass index 
Table 2. Multiple logistic regression analysis of factors associated with fever

\begin{tabular}{lcc}
\hline & Multivariate analysis & $\boldsymbol{p}$-value \\
\hline Sex $(\mathrm{M}: \mathrm{F})$ & $1.238(0.291-5.272)$ & 0.772 \\
Age & $0.967(0.927-1.008)$ & 0.115 \\
Disease & & 0.081 \\
$\quad$ Trauma & \\
DD & $0.302(0.093-0.982)$ & 0.047 \\
$\quad$ Tumor & $2.089(0.195-22.413)$ & 0.543 \\
Laminectomy & $10.251(2.550-36.488)$ & 0.000 \\
Medical disease & $2.465(0.718-8.461)$ & 0.152 \\
\hline
\end{tabular}

Values are presented as odds ratio (95\% confidence interval). M : male, F : femal, DD : degenerative disease

Table 3. Small groups head-to-head analysis between laminectomy and floating laminoplasty

\begin{tabular}{lccc}
\hline & $\begin{array}{c}\text { Laminectomy } \\
(\mathbf{n}=59)\end{array}$ & $\begin{array}{c}\text { Laminoplasty } \\
(\mathbf{n}=53)\end{array}$ & $p$-value \\
\hline $\begin{array}{l}\text { Delayed postoperative } \\
\text { fever }\end{array}$ & 24 & 4 & 0.000 \\
\hline
\end{tabular}

\section{DISCUSSION}

Most early postoperative fever is caused by surgically stimulated inflammation and resolves spontaneously. However, surgeons associate this fever with infection and therefore administer prophylactic antibiotics. Rates of infection of the surgical site have been reported to be higher following posterior cervical spine surgery (2.9-18.2\%) than following anterior cervical spine surgery ${ }^{14,20,22,28)}$. Two factors that commonly trigger an evaluation of bacterial infection are 1) fever after the third postoperative day and 2) a temperature above $39^{\circ} \mathrm{C}$. However, this practice has not been supported by high-quality clinical research $^{2,8,26)}$. In this study, of the 119 consecutive patients who underwent posterior cervical surgery, 28 (24.3\%) developed delayed postoperative fever, whereas only one $(0.8 \%)$ developed surgical site infection. Between pathologic and non-pathologic fever groups, the difference in treatment modality is whether additional antibiotic therapy was administered after prophylactic antibiotics. Pathologic fever was defined as that in which the cause of fever was identified as in-

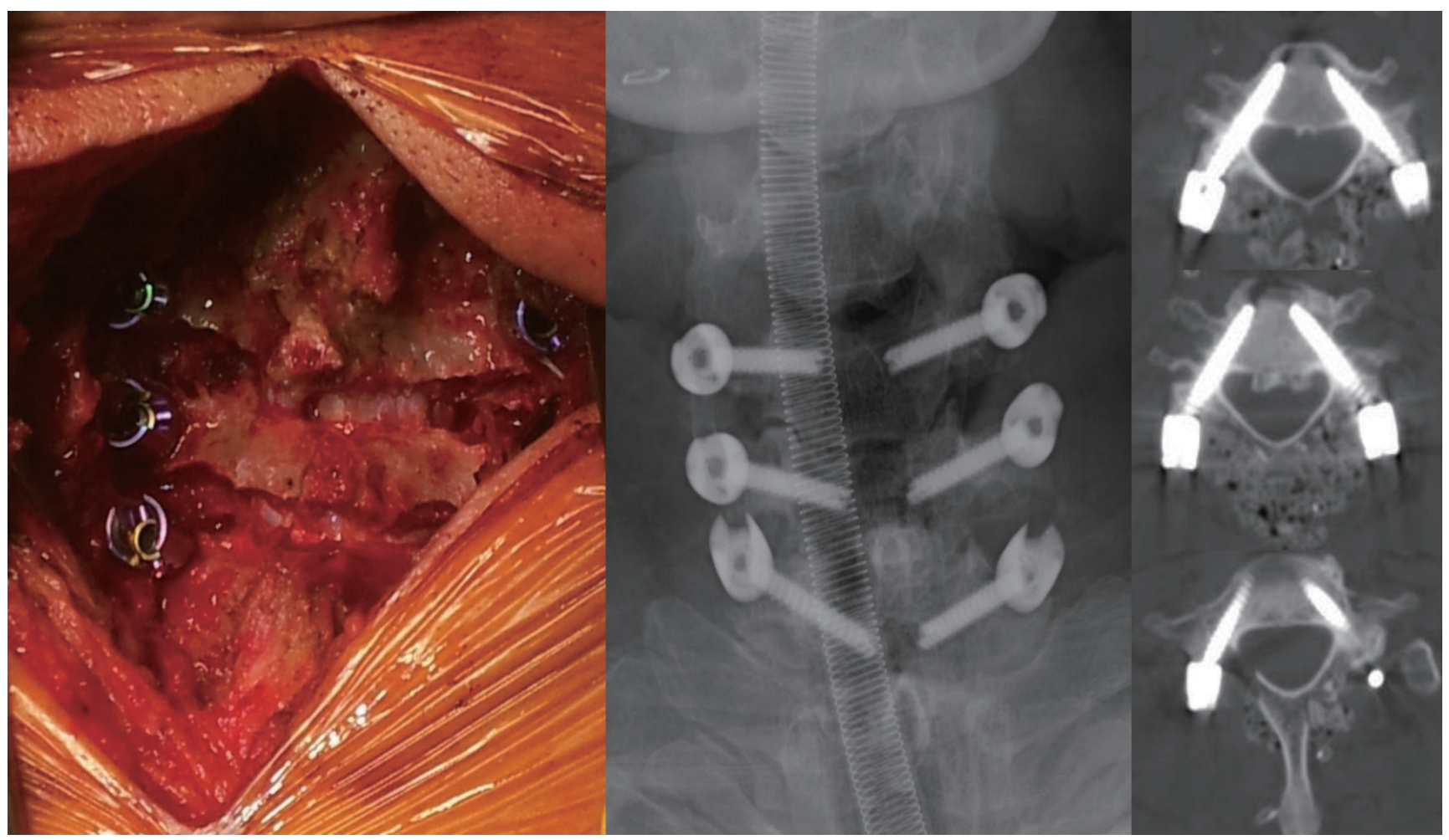

Fig. 2. Illustration of the facetectomy preserving lamina method used to decompress foraminal stenosis and obtain a wide fusion bed, including the facet, lateral mass, and lamina, to achieve robust posterolateral fusion. This method may also reduce the dead space and seroma by preserving an anatomical barrier between the dura and the muscle. 
fectious by the patient's culture study, and additional antibiotic treatment was started. On the other hand, non-pathologic fever patients did not receive additional antibiotics.

The overall incidence of non-pathologic delayed fever after general spine surgery was $13.2 \%{ }^{23}$. To date, there is no literature reporting delayed fever following posterior cervical spine surgery. To the best of our knowledge, this is the first study on homogeneous surgical methods limited to posterior cervical fusion. Previous studies have found that long operation times are associated with a higher prevalence of postoperative fever ${ }^{3,5,24}$. Moreover, in our previous study we reported that a relatively bigger surgery requiring prolonged operation time is a significant risk factor for postoperative non pathologic fever $^{233}$. In that study, the operation time could have been a risk factor because it was analyzed on various surgical methods at various surgical levels within the broad category of general spine surgery. However, in this study we included very homogeneous surgical methods that only involved posterior fusion using CPS for the cervical spine.
Therefore, the operation time of each patient was relatively uniform and there was no significant difference in the operation time according to the occurrence of postoperative fever.

All 112 patients included in this study underwent posterior fusion surgery using CPS. This technique has some disadvantages, such as the fact that CPS was inserted through a laterally located starting point and made a large medial angle, similar to an anatomical cervical pedicle lateral angle ${ }^{18)}$. This may have resulted in a larger dead space under the incision, leading to postoperative non-pathologic fever despite the absence of infection $^{23)}$.

Obliteration of the dead space may facilitate wound healing, with careful drainage or obliteration of all dead spaces within a wound regarded as an almost universally accepted precept of surgery ${ }^{6}$. Our previous study of non-pathologic fever in patients who underwent general spinal surgery strongly suggested that surgical site inflammation induced by seroma after

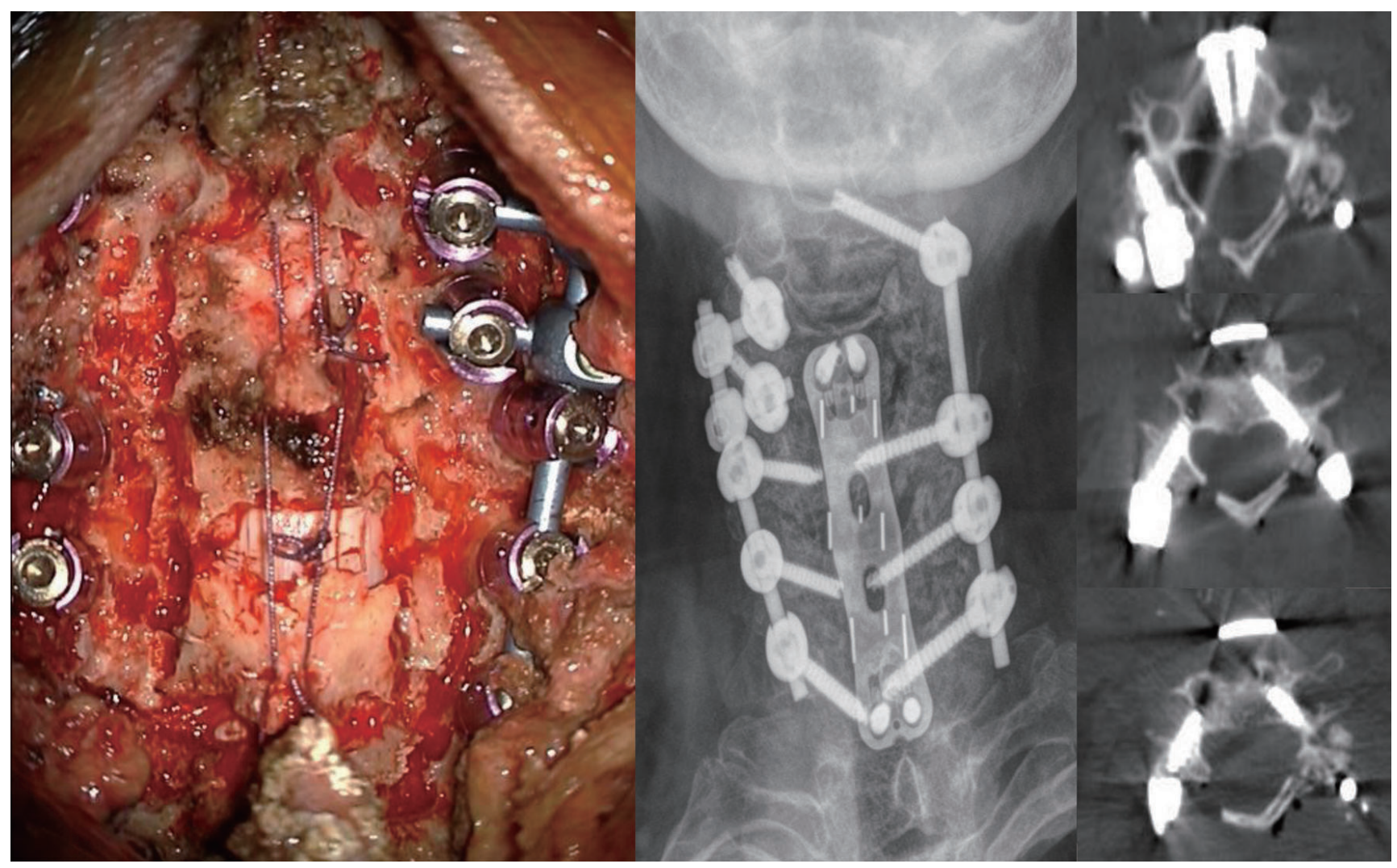

Fig. 3. Illustration showing the method used for floating laminoplasty. Parallel bony gutters were made on both sides of the lateral mass-lamina junction by drilling with a match head shaped burr. The fractured laminae anchored absorbable suture (Coated Vicryl Plus 1-0; Ethicon, Somerville, NY, USA) through the spinous process to maintain lamina elevation. A postoperative CT axial scan showed sufficient cord decompression after floating laminoplasty. The right C2 and C3 pedicle screws were converted to lateral mass screws because ball-tip probing suggested a pedicle breach. CT: computed tomography. 
drain catheter removal was the cause of fever during the late acute and subacute postoperative periods. High volumes of hematoma or seroma after drain catheter removal in patients who undergo more extensive surgery may also cause fever and tissue trauma, depending on when fever occurs ${ }^{23)}$. In contrast, use of a drain at the surgical site was found to be unrelated to postoperative hematoma formation and wound dehiscence ${ }^{11)}$. The incidence of postoperative non-pathologic fever after laminectomy was significantly higher than in patients who did not undergo laminectomy. Results from small group head-to-head analysis showed that postoperative non-pathologic fever occurred in 24 of $59(40.7 \%)$ patients who underwent laminectomy and in four of $53(7.5 \%)$ patients who underwent laminoplasty ( $p<0.001$, Table 3 ). The OR of laminectomy was 10.25 (Table 2). Laminectomy may result in a wider dead space between muscle and dura, with a seroma more likely to be present in this space. These results are in agreement with those of previous studies.

Although minimally invasive muscle preserving laminectomy techniques have been recently introduced, these procedures include decompression only without fusion ${ }^{16,25)}$. Cervical laminectomy with posterior fusion is generally known to be a more invasive surgery and have a higher morbidity than laminoplasty ${ }^{15)}$. This is not surprising as laminectomy with fusion requires additional muscle exposure, spinal fixation, and bone arthrodesis, which can result in greater intraoperative blood loss and postoperative pain ${ }^{10,27)}$. In this study, we only included patients who underwent posterior cervical fusion using CPS. Because of the higher incidence of non-pathologic postoperative fever associated with surgery-induced dead space, we suggest that laminectomy is a more extensive procedure than laminoplasty if combined with fusion.

Patients who did not undergo laminectomy included 1) patients with foraminal stenosis who underwent facetectomy with a posterior approach (Fig. 2), 2) patients with sufficient cord decompression achieved by reduction only and instrumentation for cervical subluxation and dislocation, and 3) patients with cervical spondylomyelopathy who underwent laminoplasty (Fig. 3). These methods are superior to laminectomy in reducing dead space and preserving the original anatomical structure between the dura and muscles. Most early postoperative fever is caused by surgery-induced inflammation ${ }^{9,12,19)}$. Thus, surgery that preserves the lamina may help to reduce seromas and inflammatory stimuli associated with the dead
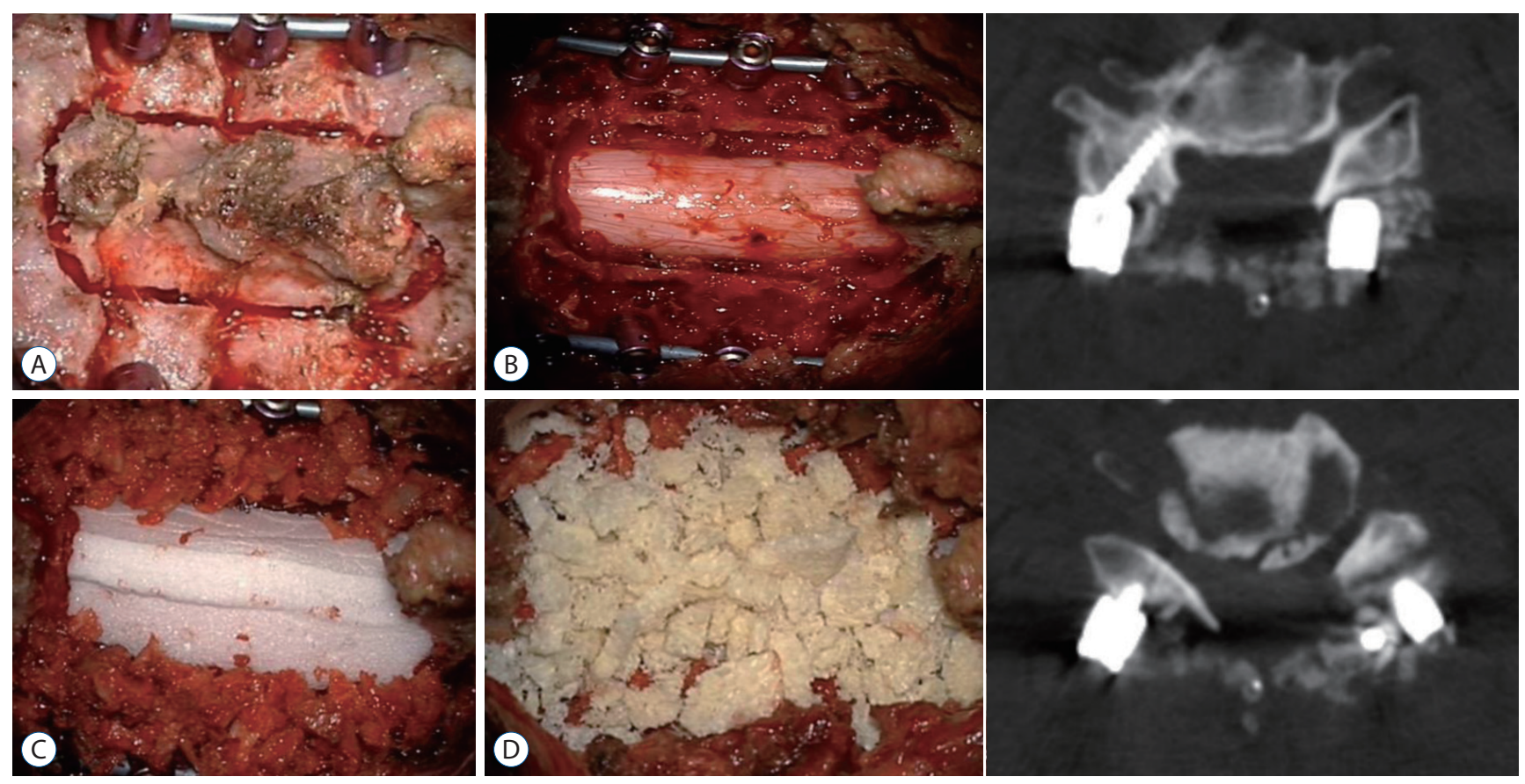

Fig. 4. Illustration showing cervical total laminectomy and posterolateral fusion after screw fixation. A and B : Dura was exposed after making a gutter and removing the lamina. C : Before the bone graft, Gelfoam was placed on the boundary between the dura and the bone graft. D : Local bone harvested from the lamina and the allobone were grafted onto the lateral mass and Gelfoam. Postoperative CT showed low density dead space between the cord and the bone graft. CT : computed tomography. 
space, reducing the incidence of postoperative fever (Fig. 4). Moreover, the higher incidence of postoperative fever following more extensive or trauma surgery may be caused by a greater degree of tissue inflammation ${ }^{1,2,13)}$.

We developed a laminoplasty method to reduce the dead space and create a barrier between the dura and muscle. In the first step, we formed a parallel gutter with a match headshaped burr (Legend Match Head - Fluted; head diameter, 1.7 mm; Medtronic-Sofamor Danek Inc., Memphis, TN, USA) on both sides of the lamina and made it fractured. The lamina was then withdrawn dorsally using the bulged cord. Finally, to maintain lamina elevation, the fractured laminae were anchored using absorbable sutures (Coated Vicryl Plus 1-0; Ethicon, Somerville, NY, USA) through a spinous process. This technique differed from the open-door method of laminoplasty by providing for symmetrical muscle closure in the midline. In addition, this method reduced the dead space by minimizing the space between the lamina and surrounding structures (Fig. 3).

This study had several limitations, including its retrospective design, inclusion of patients treated at a single center by a single surgeon, short follow-up period, and the small sample size.

\section{CONCLUSION}

Of the 112 patients who underwent posterior cervical fusion surgery using CPS, 28 (25.0\%) developed postoperative fever without infection after 4 days. These results suggest that postoperative fever is relatively common following posterior fusion surgery, especially when laminectomy is performed.

\section{CONFLICTS OF INTEREST}

No potential conflict of interest relevant to this article was reported.

\section{INFORMED CONSENT}

This type of study does not require informed consent.

\section{AUTHOR CONTRIBUTIONS}

\author{
Conceptualization : JHP, SWR, SRJ \\ Data curation : HBK, SKJ \\ Formal analysis : SKJ, SL \\ Methodology : JHP, SWR, SRJ \\ Project administration : SWR, SRJ \\ Visualization : SL, JHP \\ Writing - original draft : SL \\ Writing - review \& editing : SL, JHP
}

\section{ORCID}

$\begin{array}{ll}\text { Subum Lee } & \text { https://orcid.org/0000-0003-4732-8137 } \\ \text { Sang Ku Jung } & \text { https://orcid.org/0000-0002-9606-0440 } \\ \text { Hong Bum Kim } & \text { https://orcid.org/0000-0002-9362-9101 } \\ \text { Sung Woo Roh } & \text { https://orcid.org/0000-0001-6562-4154 } \\ \text { Sang Ryong Jeon } & \text { https://orcid.org/0000-0002-8340-7978 } \\ \text { Jin Hoon Park } & \text { https://orcid.org/0000-0002-0903-3146 }\end{array}$

\section{References}

1. Andres BM, Taub DD, Gurkan I, Wenz JF : Postoperative fever after total knee arthroplasty: the role of cytokines. Clin Orthop Relat Res (415) : 221-231, 2003

2. Badillo AT, Sarani B, Evans SR : Optimizing the use of blood cultures in the febrile postoperative patient. J Am Coll Surg 194 : 477-487; quiz 554-556, 2002

3. Blumstein GW, Andras LM, Seehausen DA, Harris L, Ross PA, Skaggs $\mathrm{DL}$ : Fever is common postoperatively following posterior spinal fusion: infection is an uncommon cause. J Pediatr 166 : 751-755, 2015

4. Chon H, Park JH : Cervical vertebral body fracture with ankylosing spondylitis treated with cervical pedicle screw: a fracture body overlapping reduction technique. J Clin Neurosci 41 : 150-153, 2017

5. Clark JA, Bar-Yosef S, Anderson A, Newman MF, Landolfo K, Grocott HP : Postoperative hyperthermia following off-pump versus on-pump coronary artery bypass surgery. J Cardiothorac Vasc Anesth 19 : 426429, 2005

6. De Holl D, Rodeheaver G, Edgerton MT, Edlich RF : Potentiation of infection by suture closure of dead space. Am J Surg 127 : 716-720, 1974

7. Galicier $\mathrm{C}$, Richet $\mathrm{H}$ : A prospective study of postoperative fever in a general surgery department. Infect Control $6:$ 487-490, 1985

8. Garibaldi RA, Brodine S, Matsumiya S, Coleman M : Evidence for the non-infectious etiology of early postoperative fever. Infect Control 6 : 273-277, 1985 
9. Guinn S, Castro FP Jr, Garcia R, Barrack RL : Fever following total knee arthroplasty. Am J Knee Surg 12 : 161-164, 1999

10. Heller JG, Edwards CC 2nd, Murakami H, Rodts GE : Laminoplasty versus laminectomy and fusion for multilevel cervical myelopathy: an independent matched cohort analysis. Spine (Phila Pa 1976) 26 : 13301336, 2001

11. Herrick DB, Tanenbaum JE, Mankarious M, Vallabh S, Fleischman E, Kurra $\mathrm{S}$, et al. : The relationship between surgical site drains and reoperation for wound-related complications following posterior cervical spine surgery: a multicenter retrospective study. J Neurosurg Spine 29 : 628-634, 2018

12. Hobar PC, Masson JA, Herrera R, Ginsburg CM, Sklar F, Sinn DP, et al. : Fever after craniofacial surgery in the infant under 24 months of age. Plast Reconstr Surg 102 : 32-36, 1998

13. Kiragu AW, Zier J, Cornfield DN : Utility of blood cultures in postoperative pediatric intensive care unit patients. Pediatr Crit Care Med 10 : 364-368, 2009

14. Kwon BK, Fisher CG, Boyd MC, Cobb J, Jebson H, Noonan V, et al. : A prospective randomized controlled trial of anterior compared with posterior stabilization for unilateral facet injuries of the cervical spine.

J Neurosurg Spine 7 : 1-12, 2007

15. Lau D, Winkler EA, Than KD, Chou D, Mummaneni PV : Laminoplasty versus laminectomy with posterior spinal fusion for multilevel cervical spondylotic myelopathy: influence of cervical alignment on outcomes.

J Neurosurg Spine 27 : 508-517, 2017

16. Lee BJ, Park JH, Jeon SR, Roh SW, Rhim SC, Jung SK : Posterior cervical muscle-preserving interspinous process approach and decompression: more minimally invasive and modified shiraishi's selective laminectomy.

World Neurosurg 133 : e412-e420, 2020

17. Lee JK, Jung SK, Lee YS, Jeon SR, Roh SW, Rhim SC, et al. : Analysis of the fusion and graft resorption rates, as measured by computed tomography, 1 year after posterior cervical fusion using a cervical pedicle screw. World Neurosurg 99 : 171-178, 2017

18. Lee S, Seo J, Lee MK, Jeon SR, Roh SW, Rhim SC, et al. : Widening of the safe trajectory range during subaxial cervical pedicle screw placement: advantages of a curved pedicle probe and laterally located starting point without creating a funnel-shaped hole. J Neurosurg Spine 27 : 150-
157, 2017

19. Livelli FD Jr, Johnson RA, McEnany MT, Sherman E, Newell J, Block PC, et al. : Unexplained in-hospital fever following cardiac surgery. Natural history, relationship to postpericardiotomy syndrome, and a prospective study of therapy with indomethacin versus placebo. Circulation 57 : 968-975, 1978

20. Memtsoudis SG, Hughes A, Ma Y, Chiu YL, Sama AA, Girardi FP : Increased in-hospital complications after primary posterior versus primary anterior cervical fusion. Clin Orthop Relat Res 469 : 649-657, 2011

21. Park JH, Jeon SR, Roh SW, Kim JH, Rhim SC : The safety and accuracy of freehand pedicle screw placement in the subaxial cervical spine: a series of 45 consecutive patients. Spine (Phila Pa 1976) 39 : 280-285, 2014

22. Sebastian A, Huddleston P 3rd, Kakar S, Habermann E, Wagie A, Nassr $A$ : Risk factors for surgical site infection after posterior cervical spine surgery: an analysis of 5,441 patients from the ACS NSQIP 2005-2012. Spine J 16 : 504-509, 2016

23. Seo J, Park JH, Song EH, Lee YS, Jung SK, Jeon SR, et al. : postoperative nonpathologic fever after spinal surgery: incidence and risk factor analysis. World Neurosurg $103:$ 78-83, 2017

24. Sharp NE, Alemayehu H, Desai A, Holcomb GW 3rd, St Peter SD : Fever after redo Nissen fundoplication with hiatal hernia repair. J Surg Res 190 : 594-597, 2014

25. Shiraishi T, Kato M, Yato Y, Ueda S, Aoyama R, Yamane J, et al. : New techniques for exposure of posterior cervical spine through intermuscular planes and their surgical application. Spine (Phila Pa 1976) 37 : E286-E296, 2012

26. Theuer $C P$, Bongard FS, Klein SR: Are blood cultures effective in the evaluation of fever in perioperative patients? Am J Surg 162 : 615-618; discussion 618-619, 1991

27. Varthi AG, Basques BA, Bohl DD, Golinvaux NS, Grauer JN : Perioperative outcomes after cervical laminoplasty versus posterior decompression and fusion: analysis of 779 patients in the ACS-NSQIP database. Clin Spine Surg 29 : E226-E232, 2016

28. Xu R, Bydon M, Sciubba DM, Witham TF, Wolinsky JP, Gokaslan ZL, et al. : Safety and efficacy of rhBMP2 in posterior cervical spinal fusion for subaxial degenerative spine disease: Analysis of outcomes in 204 patients. Surg Neurol Int 2 : 109, 2011 